\title{
Arabidopsis STERILE APETALA, a multifunctional gene regulating inflorescence, flower, and ovule development
}

\author{
Marina V. Byzova, ${ }^{1}$ John Franken, ${ }^{1}$ Mark G.M. Aarts, ${ }^{1}$ Janice de Almeida-Engler, ${ }^{2}$ Gilbert Engler, ${ }^{2}$ \\ Celestina Mariani, ${ }^{3}$ Michiel M. Van Lookeren Campagne, ${ }^{1}$ and Gerco C. Angenent ${ }^{1,4}$ \\ ${ }^{1}$ Department of Developmental Biology, Centre for Plant Breeding and Reproduction Research (CPRO-DLO), 6700 AA \\ Wageningen, The Netherlands; ${ }^{2}$ Laboratory of Genetics, BE-9000 Gent, Belgium; ${ }^{3}$ Department of Experimental Botany, \\ Catholic University Nijmegen, 6525 ED Nijmegen, The Netherlands
}

\begin{abstract}
A recessive mutation in the Arabidopsis STERILE APETALA (SAP) causes severe aberrations in inflorescence and flower and ovule development. In sap flowers, sepals are carpelloid, petals are short and narrow or absent, and anthers are degenerated. Megasporogenesis, the process of meiotic divisions preceding the female gametophyte formation, is arrested in sap ovules during or just after the first meiotic division. More severe aberrations were observed in double mutants between sap and mutant alleles of the floral homeotic gene APETALA2 (AP2) suggesting that both genes are involved in the initiation of female gametophyte development. Together with the organ identity gene AGAMOUS (AG) SAP is required for the maintenance of floral identity acting in a manner similar to APETALA1. In contrast to the outer two floral organs in sap mutant flowers, normal sepals and petals develop in $\mathrm{ag} / \mathrm{sap}$ double mutants, indicating that $S A P$ negatively regulates $A G$ expression in the perianth whorls. This supposed cadastral function of $S A P$ is supported by in situ hybridization experiments showing ectopic expression of $A G$ in the sap mutant. We have cloned the $S A P$ gene by transposon tagging and revealed that it encodes a novel protein with sequence motifs, that are also present in plant and animal transcription regulators. Consistent with the mutant phenotype, $S A P$ is expressed in inflorescence and floral meristems, floral organ primordia, and ovules. Taken together, we propose that $S A P$ belongs to a new class of transcription regulators essential for a number of processes in Arabidopsis flower development.
\end{abstract}

[Key Words: Arabidopsis mutant; inflorescence, flower, ovule development; transposon tagging; cadastral gene]

Received January 28, 1999; revised version accepted March 3, 1999.

Morphogenesis in higher plants originates from an undifferentiated group of cells, the meristem. After floral induction, the cells of a shoot apical meristem change in identity and form the inflorescence meristem that is characterized by a pattern of indeterminate growth and the production of flower meristems on its flanks. In Arabidopsis, these flower meristems are arranged in a spiral phyllotactic manner and are, unlike inflorescence meristems, determined. The flower meristems produce floral organ primordia in a precise number and pattern. Arabidopsis flowers are composed of four sepals in the first whorl, four petals in the second whorl, six stamens in the third whorl, and a pistil in the center of the flower. Inside the pistil, which is formed by the congenital fusion of two carpels, new primordia initiate and differentiate into the ovules. The initiation of primordia and the

${ }^{4}$ Corresponding author.

E-MAIL G.C.Angenent@CPRO.DLO.NL; FAX 31-317-41-80-94. specification of their identity require a complex network of regulatory genes. A number of these regulatory genes has been isolated from Arabidopsis using molecular genetic approaches (for review, see Weigel 1995). Despite the identification of these genes and extensive studies in recent years, missing pieces in the puzzle limit our understanding of the interactions between the genes involved in flower ontogeny.

The meristem identity genes $L E A F Y(L F Y)$ (Weigel et al. 1992) and APETALA1 (AP1) (Mandel et al. 1992) from Arabidopsis are involved in the establishment of the floral meristem and mutations in these two genes cause a partial conversion of a floral meristem into an inflorescence meristem. Strong ap1 mutants produce highly branched, inflorescence-like flowers with ectopic secondary flowers in the axils of the first whorl organs (Irish and Sussex 1990; Mandel et al. 1992). LFY and AP1 act synergistically together with other floral meristem identity genes, among which the APETALA2 (AP2) gene (Jo- 
fuku et al. 1994). The AP2 gene has a central role in the network of genes that control the establishment and maintenance of floral meristem and organ identity. In addition to its function as a flower meristem identity gene, AP2 specifies whorl 1 and 2 organ identity. Furthermore, it controls the temporal and spatial expression of the homeotic gene AGAMOUS $(A G)$ in the perianth floral whorls (Bowman et al. 1991; Drews et al. 1991) and in the ovule (Modrusan et al. 1994). Finally, aberrations in the seed coat of ap2 mutants demonstrate that AP2 is also required for proper seed development (Jofuku et al. 1994). The homeotic gene $A G$ can also be regarded as a multifunctional gene that controls at least three critical aspects of flower development (Yanofsky et al. 1990; Bowman et al. 1991; Mizukami and Ma 1997). First, it specifies stamen and carpel identity. Secondly, it is essential for floral meristem determination, as ag mutants are characterized by indeterminate floral growth, reiterating the floral program inside the flower. Third, as was proposed by the ABC model (Coen and Meyerowitz 1991), AG negatively regulates the AP2 gene activity in stamens and carpels. This regulation does not appear to be at the transcriptional level as $A P 2$ mRNA accumulation coincides with $A G$ expression in the inner two floral whorls (Jofuku et al. 1994).

Several genes that are functional during floral meristem determination and flower organogenesis participate in ovule and seed development as well. Sometimes their function is masked by other genes because of redundancy. Also the Arabidopsis gene SUPERMAN (SUP) acts at different stages during flower development. It specifies the boundary between whorl three and four organs (Sakai et al. 1995) as well as the growth of integuments, the cell layers that surround the nucellus of the ovule (Gaiser et al. 1995). As a final example, the AINTEGUMENTA (ANT) gene is also involved in the development of both flower organs and ovules (Elliott et al. 1996; Klucher et al. 1996).

In this report, we describe a novel Arabidopsis mutant, sterile apetala (sap), which is affected in inflorescence and flower and ovule development. The SAP gene was cloned by transposon tagging and the deduced amino acid sequence suggests that it acts most likely as a transcription regulator. Here, we demonstrate that $S A P$, in concert with $A G$, plays a role in the maintenance of floral fate in the flower. Additionally, analysis of mutant phenotypes and expression analysis revealed that $S A P$ negatively controls $A G$ in the inflorescence meristem and outer floral whorls. Furthermore, the observed aberrations in the ovule suggest that $S A P$ is essential for the initiation of meiotic divisions during megasporogenesis. Together, these results indicate that $S A P$ is a novel key regulator involved in several distinct steps of flower morphogenesis.

\section{Results}

\section{Identification of the sap mutant}

A large population of Arabidopsis plants containing the En/Spm-I/dSpm transposable element system (Aarts et al. 1995) was screened for mutants with reduced fertility. Plants with small or undeveloped siliques were selected. One mutant appeared to be male and female sterile as determined by reciprocal crosses to wild-type plants. This mutant (Fig. 1B) was designated sap because of the resemblance of its flowers to those of the homeotic Arabidopsis mutant ap2 (Komaki et al. 1988; Kunst et al. 1989; Bowman et al. 1991; Jofuku et al. 1994).
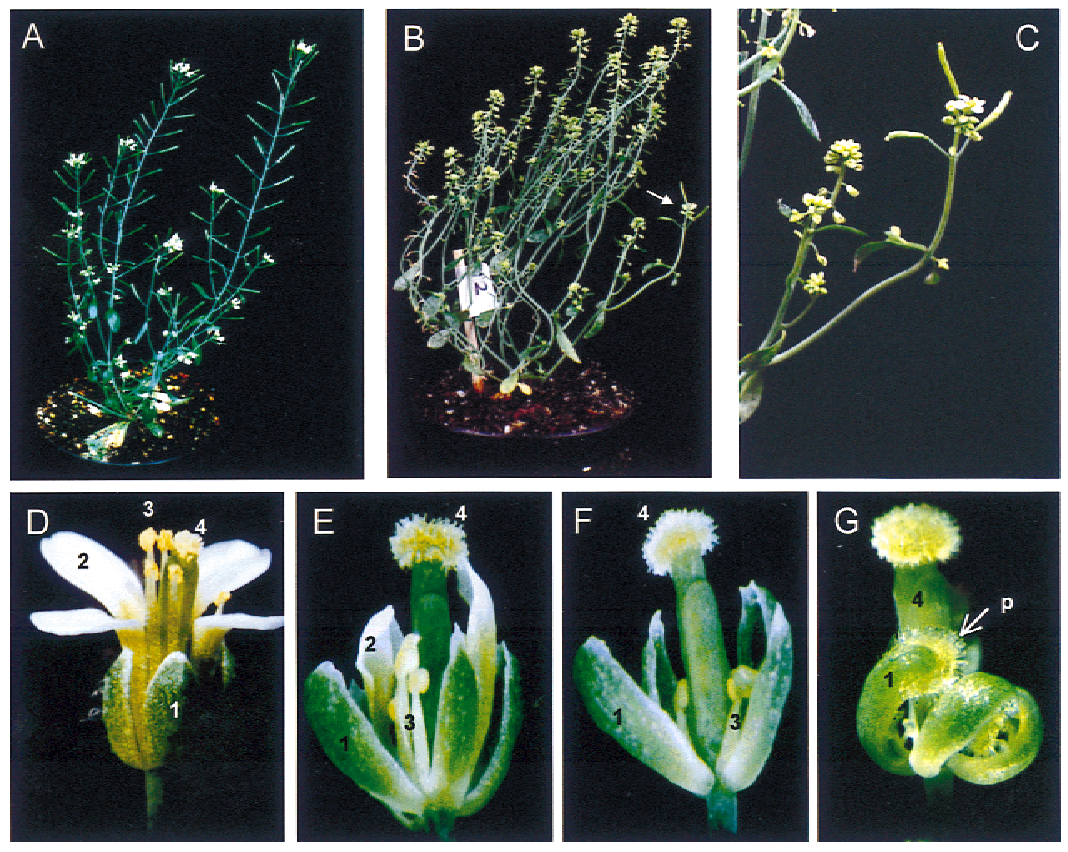

Figure 1. Phenotype of wild-type and sap mutant plants and flowers: $(A)$ phenotype of a wild-type Arabidopsis thaliana plant. (B) Phenotype of a unstable sap mutant plant. Plants are sterile and internodes are shorter than in wild-type plants. Revertant branch can be observed (arrow). (C) Wildtype revertant branch (left) and a branch with a sap mutant phenotype (right). Reversion to wild-type phenotype occurred by excision of the transposable element from the sap::I/dSpm allele. (D) Phenotype of a wild-type flower. (E) Phenotype of a sap early-arising flower. Sepals resemble wildtype sepals. Petals are short and narrow. Stamens are short with aberrant anthers. Petals and stamens are reduced in number. (F) Phenotype of a sap late-arising flower. First-whorl organs are sepals with occasionally stigmatic at the tips. Petals are absent. Stamens and pistil are reminiscent with whorl -3 and -4 organs in early-arising sap flowers. $(G)$ Phenotype of a severely affected late-arising flower. First-whorl organs are carpels with stigmatic papillae (p) and ovules at the inner side. Whorl-2 and -3 organs are absent. 
Revertant branches were observed frequently on sap mutant plants producing wild-type flowers (Fig. 1C). This instability indicates that the mutation was caused by the insertion of an $I / d S p m$ transposable element into the $S A P$ gene, whose function was restored upon excision. Flowers from several revertant branches were selfpollinated and the progenies (35 plants each) were analyzed for sap mutant segregation. All progenies showed approximately a 3:1 ratio of wild-type to mutant phenotype, indicating that the parental revertant flower was heterozygous for $S A P$ (Sap,sap::I/dSpm) and that the mutation was inherited in a Mendelian fashion as a recessive trait.

sap mutant is affected in inflorescence architecture and floral structure

In the sap mutant, inflorescences are produced with at least two to three times shorter internodes than in wildtype plants (Fig. 1C). Consequently, the flowers are positioned closer to each other. Mild-to-severe defects were observed in sap mutant flowers, depending on the age of the plant (Fig. 1E-G). The first whorl organs of sap flowers show a homeotic transformation from sepal to carpelloid with increasing severity in later arising flowers. Petals in the second whorl of the early-arising flowers are narrower and shorter than in wild-type flowers. In laterarising flowers the petals are completely absent and the four first-whorl organs are transformed into carpels bearing ovules at the inner side (Fig. 1G). These aberrations in the outer two whorls of sap flowers resemble those observed in the flowers of the Arabidopsis mutant ap2 (Komaki et. al. 1988; Kunst et. al. 1989; Jofuku et al. 1994). The number of stamens in the third whorl of sap flowers is reduced from six to four (missing the lateral stamens) or two. These stamens have shorter and thinner filaments and small degenerated anthers, which do not produce pollen. A detailed microscopic analysis showed that the tissues in the anthers did not differentiate normally (results not shown). The fourth whorl of a sap flower consists of a morphologically normal pistil with stigmatic papillae, which are longer than in wildtype plants.

\section{Ovule development is abnormal in sap mutants}

Flowers from sap plants are female sterile and never produce seeds upon pollination with wild-type pollen. To investigate whether female sterility is caused by defects in pollen-pistil interaction, we followed the pollen tube growth in sap pistils. Pollen grains were able to germinate on the stigma and the pollen tubes grew inside the pistil towards the ovary, with the formation of regular callose plugs as can be observed in wild type (Fig. 2A). However, penetration of pollen tubes into sap ovules was abolished, suggesting that the ovules were aberrant (Fig. 2B,C). Failure of pollen tube penetration was also observed by Hülskamp et al. (1995) in the Arabidopsis female sterile mutants bell1, short integuments (sin1), $47 \mathrm{H} 4$, and 54D12.
Surprisingly large accumulation of callose was observed in mature sap ovules. To study this abnormal callose deposition and the ontogeny of sap ovules in more detail, we performed a microscopic analysis on ovules of various developmental stages. Detailed analyses of ovule development in Arabidopsis have been reported previously (Robinson-Beers et al. 1992; Modrusan et al. 1994; Schneitz et al. 1995). In wild-type Arabidopsis ovules at stage 9 (Smyth et al. 1990), a megasporocyte is differentiated in the nucellus (Fig. 2D). Shortly afterward, at stage 10 , when the formation of the two integuments is initiated, the megasporocyte undergoes two cycles of meiotic divisions resulting in four megaspores (megasporogenesis, Fig. 2E). Only one out of the four megaspores is functional and survives and forms, after three cycles of nuclear division and cellularization (megagametogenesis), a mature embryo sac (Fig. 2F). During megagametogenesis, both integuments continue to grow and cover the nucellus completely by late stage 12 .

Ovule development in the sap mutant is indistinguishable from wild type at early stages before meiosis (Fig. 2G). All sporophytic tissues, such as nucellus, inner and outer integuments, and funiculus develop normally (Fig. 2H,I,L,M). The first aberrations became apparent during megasporogenesis, because a tetrad was never observed in sap ovules (Fig. 2H). In mature sap ovules, embryo sacs are absent completely and callose accumulates at the position normally occupied by the embryo sac (Fig. 2C,I).

To analyze the megasporogenesis in wild-type and in sap ovules in more detail, aniline blue staining was performed to visualize callose in newly formed cell walls (Rodkiewicz 1970; Schneitz et al. 1995). Figure 2J shows an ovule at the dyad and one at the tetrad stage in a wild-type ovary. In sap ovules, the megasporocyte undergoes the first meiotic division, but does not continue cell division. Frequently, callose does not only accumulate in the cell wall of the dyads but deposition was also observed inside the cells (Fig. 2K). Accumulation of callose inside megaspores is characteristic for cells that degenerate (Pimienta and Polito 1982; Vishnyakova 1991), which probably occurs in sap ovules at or immediately after the first meiotic division. At later stages, when the integuments extend towards the apex of the nucellus, still only two megaspores are present and they are filled with callose (data not shown). In mature sap ovules, callose accumulation is observed at the position where in wild-type ovules an embryo sac is formed (Fig. 2C).

\section{Molecular cloning of the SAP gene}

For the cloning of the $S A P$ gene, the I/dSpm transposable element that cosegregates with the sap phenotype was identified. DNA flanking this $I / d S p m$ element was amplified by an inverse polymerase chain reaction (IPCR) (Aarts 1996) and used as a probe for the screening of a wild-type Arabidopsis thaliana Landsberg erecta genomic library. A 9-kb genomic fragment was isolated. The structure of this genomic fragment and the location of 

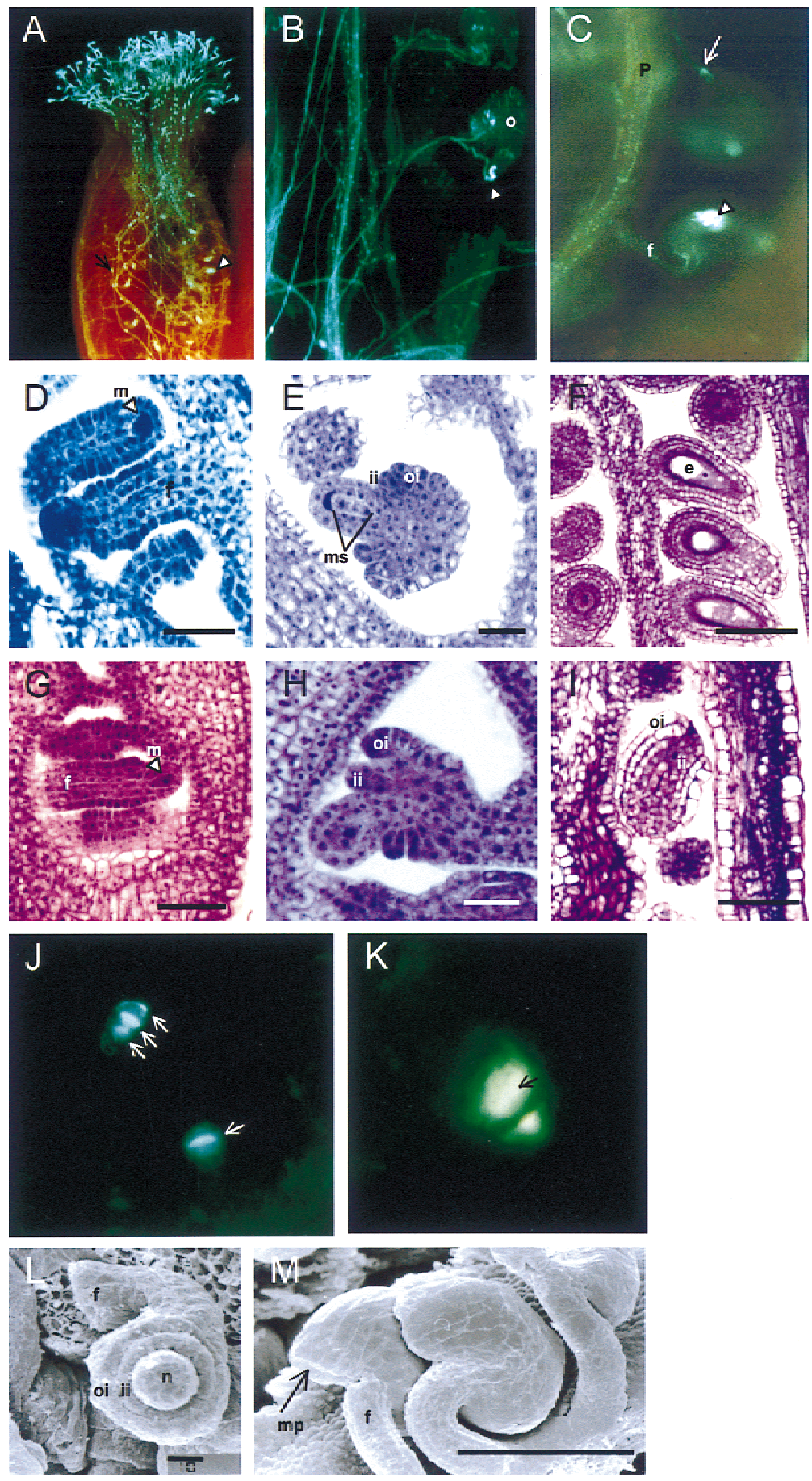

the $I / d S p m$ element insertion in SAP are illustrated in Figure 3A.

To prove that the insertion in the cloned fragment cosegregates with the sap mutant phenotype, a blot containing DNA of a segregating Sap/sap progeny was hybridized with a part of the isolated fragment as probe. All sap mutant plants (6 plants) were homozygous for the specific $I / d S p m$ element insertion, whereas all plants $(21$ plants) with a wild-type phenotype exhibited either two
Figure 2. Microscopic analysis of wild-type and sap mutant ovules. (A) UV micrograph showing pollen tube growth through a mature pistil of sap. Pollen tubes are visualized by aniline blue. Regular callose plugs inside the pollen tubes (arrow) and strong staining in ovules (arrowhead) can be seen. (B) UV micrograph showing the penetration of pollen tubes into wild-type ovules. The arrowhead points to a successful penetration into the micropyle of the ovule. $(C)$ UV micrograph of two ovules in a pollinated sap mutant plant. The upper ovule is morphologically normal and is penetrated by a pollen tube (arrow). Wild-type ovules appeared rarely in the sap mutant. They are most likely caused by somatic excision of the transposable element from the $S A P$ gene during early stages of ovule development. The lower ovule has a typical sap phenotype with a highly stained plug of callose in the center of the ovule. An arrowhead indicates this callose deposition. $(D)$ Light micrograph of developing wild-type ovules at stage 9 (Smyth et al. 1990). The megasporocyte is indicated by an arrowhead. $(E)$ Light micrograph of developing wild-type ovule at stage 10 (Smyth et al. 1990). The four megaspores are formed in the nucellus after two cycles of meiotic divisions. Simultaneously, the outer and inner integuments appear. $(F)$ Light micrograph of mature wild-type ovules. Outer and inner integuments surround embryo sacs. $(G)$ Light micrograph of developing sap ovules at stage 9 (Smyth et al. 1990). The megasporocyte is indicated by an arrowhead. $(H)$ Light micrograph of developing sap ovule at stage 10 (Smyth et al. 1990). Megasporogenesis is arrested and only two megaspores can be detected. (I) Light micrograph of a mature sap ovule. Embryo sac is absent, but outer and inner integuments are indistinguishable from wild-type integuments. $(J)$ and $(K)$ UV micrographs of aniline blue stained ovules of wild-type plants $(J)$ and sap mutant plants $(K)$. $(J)$ A tetrad and dyad are visible in the wild-type ovules. Callose deposition is indicated by an arrow. $(K)$ Stage 10 (Smyth et al. 1990) of a sap ovule with an aberrant dyad. Callose accumulates inside the megaspores as indicated by an arrow. $(L)$ and $(M)$ Scanning electron micrographs of stage 10 sap ovules $(L)$ and mature sap ovules $(M)$. The sporophytic tissues develop normally and the integuments enclose the nucellus completely. (o) Ovule; (m) megasporocyte; (ms) megaspores; (oi) outer integument; (ii) inner integument; (f) funiculus; (e) embryo sac; (p) placenta; (mp) micropyle. Bar, $10 \mu \mathrm{m}(D, E, G, H, L) ; 50 \mu \mathrm{m}(F, I) 100$ $\mu \mathrm{m}(M)$. hybridizing fragments or only one band representing the wild-type allele (data not shown).

Excision of an I/dSpm element often leads to footprints in the form of short DNA deletions or additions (Aarts et al. 1995). Therefore, a few stable sap mutants and Sap revertant plants with a wild-type phenotype were chosen for transposon-footprint analysis. The DNA sequences of the derived alleles are shown in Figure 3C. The stable sap plant $(S A P-5.510)$ carries a 4-bp addition, 
A

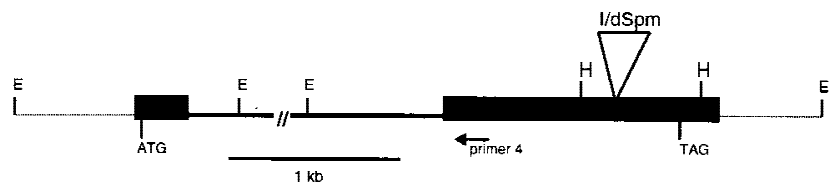

B

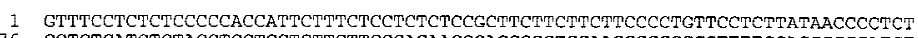

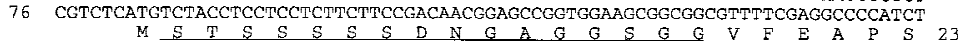

151 CCATCCCGCCCTCGCCGCGGAGCCAACGATGTTTGGCCGGAGCCTTTTCTTGAATCTCTCGCCGTTCAAGTTGCC $\begin{array}{llllllllllllllllllllllllll}P & S & R & P & R & R & G & A & N & D & V & W & P & E & P & F & L & E & S & I & A & Y & Q & V & A & 48\end{array}$

226 GTTAACGCTRCCACATCCGCCGGCCTCCTCGCCGCAGCTCCGGCTCTTGCCAACGTTTTTCGGGTTGCACCACG

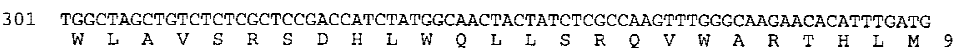

376 CACGACACGTGGCGGGACGAGTTCATCTACCGTCATCGGACGGCTAGAAACTTCCGGACGCGTACTCACACCTAC

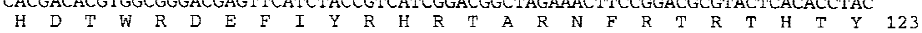

451 TTCACTCTCCAATTTGACCCGTCTGATGTGGACGAGCCTGATAGTCTCTCTTGCCGTTGTCTCACCCTCTCAGAC

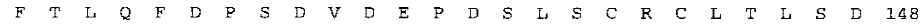

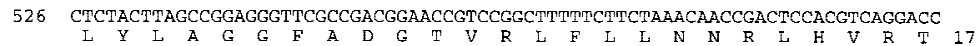

601 TTACGGCCACCTCTACGTGACCCCTTTGGTAGATTCTCACGAGCCGTCTCAGGCATTGTTATCTCCGACTCAAGG

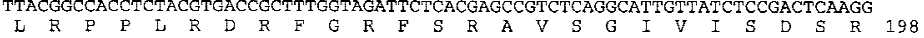

676 CTCACGTTCGCTACGATGGACGGAGACATCCACGTGGCGGAAATAGACGGTGTTGGTCACACACGCACGGCTTAC

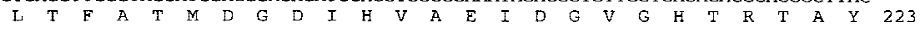

751 GCAGGAGATATAGTTAACGACGGTGCGTTGGTAGATTTCACTGGCTGTGGACGTTGGTGGGTCGGTCTMTTCGCG

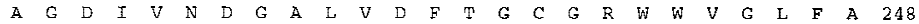

826 GGTGTGCCAGGTCGTGCCTTTCACATATGGGACTGTAACAGCGAAGAGACAACATTCGTCGGTGGTACACTCACC $G$ V P G

901 GACCCTGAAGCTGTCATGGGATGGCACACGTTAACAGAGCTAACAACGTCCCTTGGCCGTCTCAGAATCTCCGGT $\begin{array}{llllllllllllllllllllllllllll}D & \text { P } & \text { E } & \text { A } & \text { V } & \text { M } & \text { G } & \text { W } & \text { H } & \text { T } & \text { L } & \text { T } & \text { E } & \text { L } & \text { T } & \text { T } & \text { S } & \text { L } & \text { G } & \text { R } & \text { L } & \text { R } & \text { I } & \text { S } & G & 298\end{array}$

976 AACGAGACGGCGGTAGCATGCACGAGATGGAGAATCATGGTGATCGATCTAAGA.ACCAAGGAGTGATCATCGGA

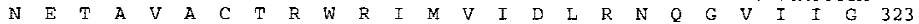

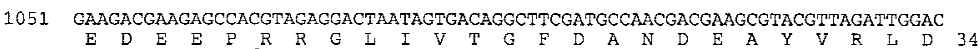

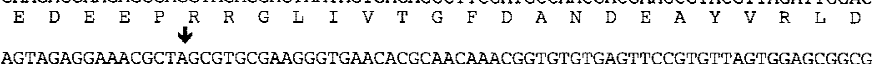

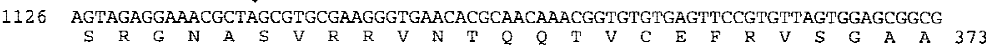

1201 CAGAGAAGAGTAATGGGTGTGTTAATAGACTGCACGCGCTAATGTGCGCAGGTGGTATAATGCGCGTGTGGGAG $\begin{array}{llllllllllllllllllllllllll}Q & R & R & V & M & G & C & V & N & R & L & H & A & L & M & C & A & G & G & I & M & R & V & W & E & 398\end{array}$

1276 GTAGAGAGAGGAGATATCTGTACAGTATTAGGGAGAGAGTAGGAGAAGTTGACGCCATTGTTGCCGATGATAGA $\begin{array}{llllllllllllllllllllllllllll}V & E & R & G & E & Y & L & Y & S & I & R & E & R & V & G & E & V & D & A & I & V & A & D & D & R & 423\end{array}$

1351 CATGTGGCGGTTGCGTCAGCTTCATCAACGGCTCAGAGTATTATACATCTATGGGATTTCGGTGCACTGTAGCGT $\mathrm{H} V \mathrm{~V}$ A $\quad$ V

1426 ACCAGATTACTAAAATTTTTTTTTTTTAACTTGAAAAAAAAGAAACTATTTTTCTCTGAAAAAGCGAAACCCTAAA

1501 CCTAGGTGTATATGTAGGGTTTCTGATTATAAATTMAATTGGGAAAGTGACGGAGGGAAGATGGTGACACGACGG

1676 TGAAATTTACAAGGGAAATTGATTCTITCTACAAAGTTCACCAAAAAATMAAGTTACTGTTTTTGTCTAAAACC

1726 GAAATGTCTMTTTTTTTTTCTTCTACTTGTAACTCTTCACTTIACTGGAGTTIATTATTTTGTATAATGGTCCA

1801 A.AAAAAAAAAA

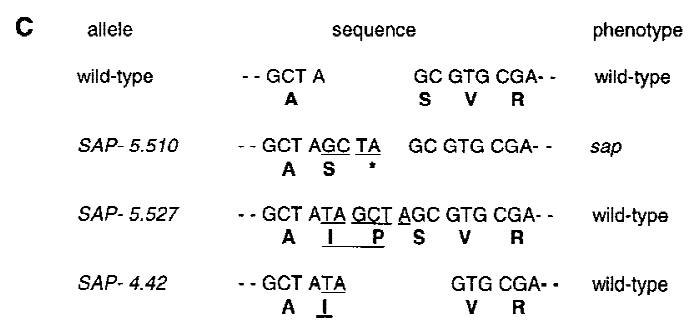

Figure 3. $S A P$ genomic structure and sequences of $S A P$ cDNA and mutant alleles. $(A)$ Genomic structure of the $S A P$ gene. Solid bars represent exons and the single intron of approximately $3 \mathrm{~kb}$ in length is indicated by an interrupted line. The locations of the start (ATG) and stop codon (GTA) are shown. The thin line represents genomic DNA outside the $S A P$ gene. The position of the $I / d S p m$ insertion is indicated by the large open triangle. Primer 4 was used for 5' RACE. (E) EcoRI; (H) HinfI restriction sites. (B) Nucleotide sequence of $S A P$ cDNA and the deduced amino acid sequence. The position of the intron is shown $(\boldsymbol{\nabla})$; the position of the $I / d S p m$ insertion is indicated $(\boldsymbol{\Downarrow})$. The serine-glysine-rich domain is underlined. $\left({ }^{*}\right)$ The stop codon of the ORF. $(C)$ Footprint alleles generated after excision of the $I / d S p m$ element from the sap:I/dSpm allele. The phenotype is either as wild-type or sap mutant plants. The sequence of the duplications is underlined. In allele SAP-5.510 a duplication of four nucleotides results in the generation of a stopcodon indicated by an asterisks. In allele $S A P-4.42$ a duplication of two nucleotides (TA) is accompanied by a GC deletion, restoring the ORF. resulting in the generation of a stop codon, whereas the footprints in the Sap plants leave the open reading frame intact (SAP-5.527 and SAP-4.42).

Taken together these data show that transposon insertion and excisions in the cloned genomic fragment correlate fully with the sap mutant phenotype. Thus, this cloned fragment contains part of the SAP gene.

The map position of the $S A P$ gene was determined by RFLP using a population of recombinant inbred line (RIL) markers (Lister and Dean 1993). It is localized on chromosome 5 , between genetic markers um579D and m247 (data not shown). This position demonstrates that the sap mutant is a novel homeotic mutant and not an allele of one of the known homeotic mutants.

\section{Sequence of the SAP gene}

The 3-kb EcoRI genomic fragment, that hybridizes with the IPCR clone, was sequenced completely. This sequence analysis combined with RT-PCR analysis /data not shown) revealed that the fragment contains the 3 'terminal exon and part of the intron of the SAP gene. Attempts to isolate a cDNA clone corresponding to the $S A P$ gene from an Arabidopsis flower-specific cDNA library (Weigel et al. 1992) were not successful, probably because of a very low and specific SAP gene expression in flowers (see below). Therefore, the $5^{\prime}$ terminal coding part of $S A P$ was identified by $5^{\prime}$ rapid amplification of cDNA ends (RACE)-PCR using poly(A) ${ }^{+}$RNA isolated from young flower buds. In this way, the $5^{\prime}$ terminal part of the SAP cDNA including a putative $5^{\prime}$-untranslated leader sequence of $81 \mathrm{bp}$ was cloned. Using this $5^{\prime}$-terminal part of the $S A P$ cDNA as probe, another EcoRI genomic fragment of $1081 \mathrm{bp}$ was isolated. Sequence analysis showed that this genomic fragment contains upstream sequences, the complete $5^{\prime}$-exon and part of the single $S A P$ intron (Fig. 3A).efficacy

As shown in Figure $3 \mathrm{~B}$, the $S A P$ cDNA has a length of $1811 \mathrm{bp}$ and contains an open reading frame for a deduced protein of 446 amino acid residues with a pre- 
dicted molecular mass of $49 \mathrm{kD}$. The coding region is followed by a 3' untranslated region of $390 \mathrm{bp}$. Based on the comparison of the genomic and cDNA sequence, it is concluded that the $S A P$ gene contains a single intron of $\sim 3 \mathrm{~kb}$. This was confirmed by comparison of fragments obtained by RT-PCR and PCR on genomic DNA using $S A P$-specific primers (data not shown).

A computer search of the available sequence databases using the BLAST program (Altschul et al. 1990) revealed no significant similarities of the predicted SAP protein sequence to known protein sequences. When we compared the SAP cDNA sequence with the EST (expressed sequence tag) database of Arabidopsis, no clear homologies were detected either. However, a further examination of the SAP protein revealed small sequence motifs that are characteristic for transcriptional regulators. A long serine-rich stretch (STSSSSS) is present at the amino terminus of the protein. Similar domains have been found in a number of eukaryotic transcription factors and it has been implicated that these sites are targets for phosphorylation (Mitchell and Tjian 1989). This amino-terminal serine-rich region is adjacent to a glycine-rich region (DNGAGGSGG). Together these two stretches compose a serine/glycine-rich domain, which is a motif often found in eukaryotic transcriptional regulators (Janssen-Timmen et al. 1989; Gashler et al. 1993). In conclusion, $S A P$ encodes a novel protein containing a few hallmarks of a transcriptional regulator.

\section{SAP is expressed predominantly in inflorescence and floral meristems and ovules}

Phenotypic analysis of sap mutant plants indicates that the $S A P$ gene product is required for inflorescence and flower and ovule development. To determine how the expression pattern of $S A P$ correlates with the sap mutant phenotype, we studied the $S A P$ mRNA distribution in wild-type Arabidopsis plants by in situ hybridization.

$S A P$ transcripts first become detectable in the inflorescence meristem, and $S A P$ remains uniformly expressed in the floral meristems throughout stages 1 and 2 of flower development (Fig. 4A,B). After stage 3, when sepal primordia have started to arise, $S A P$ expression becomes restricted to floral whorls 2,3 , and 4, whereas no hybridizing signal was detected in whorl 1 (Fig. 4B). Expression is maintained at approximately the same level in developing petals, stamens, and carpel primordia until stage 6 . After stage 6 , when the organ primordia emerge further, the level of $S A P$ expression diminishes and no $S A P$ mRNA is detectable at stage 8 (Fig. 4C). At later developmental stages $S A P$ transcript appears again in ovule primordia in the nucellus region before the initiation of integuments. When integument primordia start to arise (stage 10), the expression of SAP increases and is predominantly detectable in the developing inner and outer integuments (Fig. 4F). In expanding integuments, $S A P$ expression seems to be maintained at the same level, but it decreases at mid-stage 12 and becomes restricted to the basal part of the integuments. No expression was detected in mature ovules (data not shown).
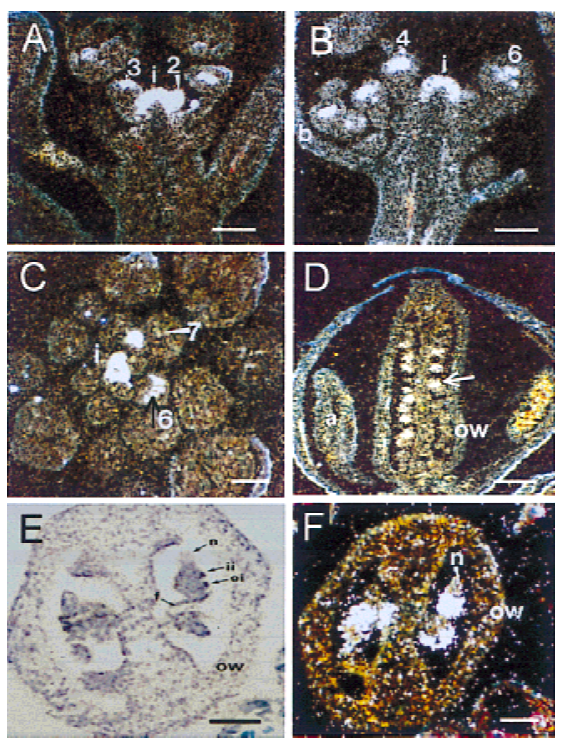

Figure 4. Expression of $S A P$ mRNA in wild-type Landsberg erecta inflorescence and flowers. Numbers refer to the stage of flower development according to Smyth et al. (1990). Expression of $S A P$ was determined by in situ hybridization with ${ }^{35}$ S-labeled antisense RNA corresponding to the SAP cDNA. Hybridization signals were viewed using dark-field microscopy. (i) Inflorescence meristem; (b) bract; (p) petal; (a) anther; (s) stigma; (ow) ovary wall; (oi) outer integuments; (ii) inner integument; (f) funiculus; (n) nucellus. $(A, B)$ Longitudinal sections through inflorescence. Strong expression is detected in the inflorescence meristem and at the flanks of the apex, corresponding to the initiation of a floral primordium and young floral buds (stages 1 and 2). At flower stages 3-4 expression is detectable in the central region between the sepal primordia. At stage 6, hybridization signals are visible in the primordia of the petals, the stamens and the central gynoecium but not in the sepals. $(C)$ Cross section through an inflorescence apex. The developing floral buds surround the inflorescence meristem in a spiral pattern. Expression is maintained throughout stages 2-5 and decreases during stage 6, whereas expression is abolished after stage 7. $(D)$ Longitudinal section of a stage-12 flower bud. Strong SAP expression is present in ovules (arrow), but not in other floral organs. $(E, F)$ Cross sections through a pistil of stage 11 imaged under bright field $(E)$ or dark-field $(F)$. Strong hybridization signals are present in the developing outer and inner integuments, and weaker signals are detectable in the nucellus. Bars, $100 \mu \mathrm{m}$ $(A-D) ; 50 \mu \mathrm{m}(E, F)$.

The in situ hybridization experiments demonstrate that the location of $S A P$ expression in wild-type Arabidopsis plants is correlated with the phenotypic aberrations observed in the sap mutant. The homeotic transformations in the first whorl of sap flowers appear to be initiated at a very early stage, because at later developmental stages when sepal primordia arise, $S A P$ expression is not detectable anymore.

To determine whether residual SAP mRNA is present in sap mutant plants, Northern blot analysis was performed using poly $(\mathrm{A})^{+}$RNA isolated from inflorescences with young flower buds at various developmental stages (0-6). Although the expression of $S A P$ is weak, accumulation of $S A P$ mRNA was detectable in wild-type inflo- 
rescences, but was abolished completely in inflorescences of the sap mutant (data not shown). Because there is a strong resemblance between the phenotypes of sap and the ap2 mutant, we reprobed the Northern blot with $A P 2$ to analyze whether the sap phenotype was partly caused by altered AP2 gene expression. However, AP2 is expressed in the sap mutant at the same level as in wildtype inflorescences (data not shown). A reciprocal Northern blot carrying mRNA from three ap2 mutant alleles (ap2-1, ap2-5, ap2-6), and probed with $S A P$, did not show difference in expression either (data not shown), indicating that there is no direct correlation between AP2 and $S A P$ expression.

\section{Interaction between SAP and homeotic genes}

Some features of the sap mutant resemble characteristics of ap2 mutants, which may suggest a possible genetic interaction between these two genes. To test this hypothesis we produced and analyzed double-mutant plants. Because it was demonstrated previously (Drews et al. 1991) that $A P 2$ is a negative regulator of $A G$, we also raised double mutants between sap mutant plants and the ag-1 mutant allele.

\section{sap/ap2 double mutants}

Several ap2 mutant alleles were used to raise double mutants with sap. We used the weak ap2-1 allele in our double-mutant studies to monitor a possible synergistic effect of $S A P$ in an ap2 mutant background. In ap2-1 flowers, leaves develop in whorl 1, a reduced number of staminoid petals are formed in the second whorl, and normal stamens and carpels develop in whorls 3 and 4, respectively (Bowman et al. 1991, Fig. 5A). As is shown in Figure 5B, sap/ap2-1 flowers possess features of both sap and ap2-1 single mutants. Whorl one organs are leaflike as in ap2-1 single mutants implying that AP2 is epistatic to $S A P$ in the first whorl. With respect to whorl two organs, the genes seem to act synergistically because sap/ap2-1 double mutants never produce second whorl organs. The morphology of the stamens resembles those of the sap single mutant. The pistil is normal morphologically though the size is somewhat reduced, resulting in a smaller number of ovules.

Like sap single mutants sap/ap2-1 plants are completely sterile. Defects in ovule development appear to be enhanced in sap/ap2-1 mutants. Microscopic analysis (Fig. 5, cf. C and D) reveals that sap/ap2-1 ovules not only lack an embryo sac, as in sap single mutants, but in addition the outer integument does not cover the inner integument and nucellus completely. This strong synergistic effect suggests that both genes are essential for normal outer integument development, in accordance with the expression patterns of $S A P$ and AP2 (Jofuku et al. 1994).

The sap single mutant shows defects in megasporogenesis, therefore we examined whole mount of sap/ ap2-1 ovules to visualize callose deposition during cell
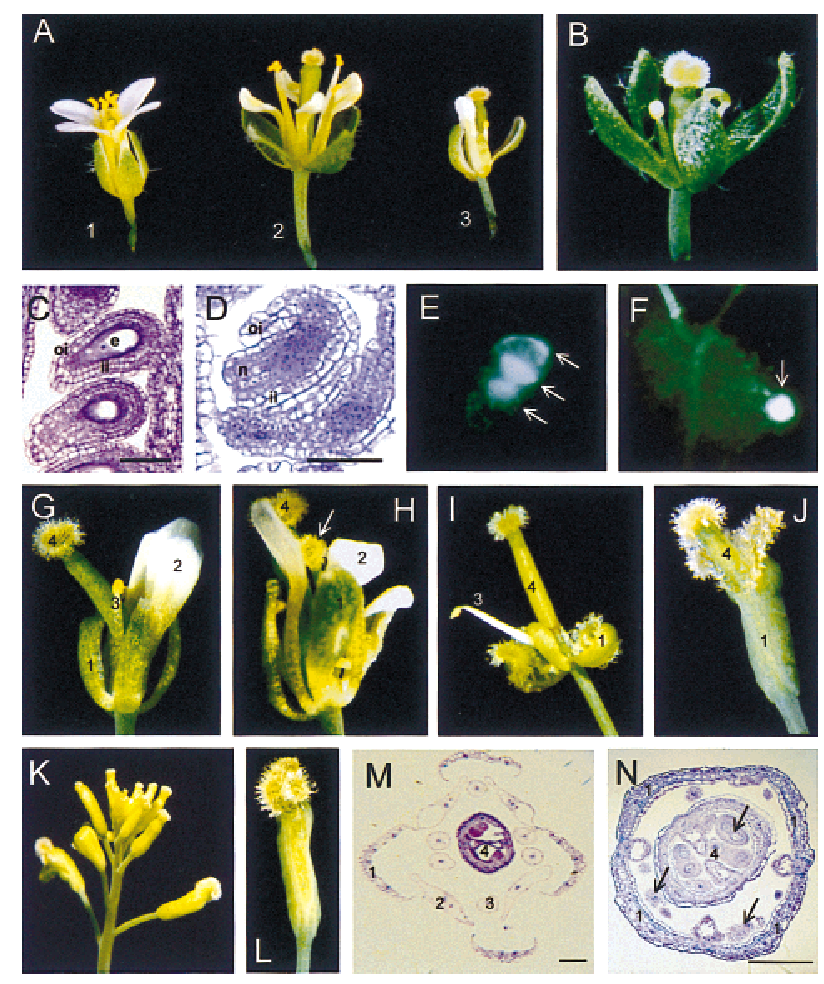

Figure 5. Phenotypes of sap/ap2 double mutants. (A) Phenotypes of wild-type (1), ap2-1 (2), and sap (3) mutant flowers. (B) Phenotype of sap/ap2-1 double mutant flower. Sepals are leaflike as in ap2-1 single mutants and petals are completely absent. The number of stamens is reduced and anthers are malformed or carpelloid. Pistil is smaller than in ap2-1 and sap single mutants. $(C)$ Longitudinal section through mature wild-type ovules. Outer and inner integuments surround the embryo sacs. (D) Longitudinal section through a mature sap/ap2-1 ovule. These ovules exhibit protruding nucellus (n) and the outer integument (oi) does not enclose the ovule completely. Bar, 50 $\mu \mathrm{m}$. (E) UV micrograph of cleared wild-type ovule at stage 9 (Smyth et al. 1990) stained with aniline blue to visualize callose deposition. A tetrad is visible and the arrows indicate callose deposition. (F) UV micrograph of a cleared sap/ap2-1 ovule at stage 9 (Smyth et al. 1990) stained with aniline blue to visualize callose deposition. Callose accumulates (arrow) in the nucellus before megaspore formation. $(G)$ Phenotype of an early-arising sap flower. $(H)$ Phenotype of an ap2-5 mutant flower. First whorl organs show carpelloid features with occasionally stigmatic tissue (arrow). Petals are reduced in size. Stamens are reduced in number but develop normally. The pistil is not affected. (I) Phenotype of an ap2-6 mutant flower. Whorl-one organs are transformed into carpels, petals are absent and the number of stamens is reduced. $(J)$ Phenotype of an early-arising ap2-5/sap double mutant flower. Four carpels are formed in whorl one, which are partially fused to a gynoecium. Petals and stamens are completely absent. The pistil contains ovules with similar aberrations as is observed in sap/ap2-1 double mutants. $(K)$ Inflorescence of an ap2-5/sap double mutant. $(L)$ Phenotype of a late-arising ap2-5/sap double mutant flower. Four completely fused carpels are formed in whorl one, which covers the central gynoecium. $(M)$ Light micrograph of a cross section through a wild-type flower. The floral whorls are indicated. The central gynoecium is composed of two fused carpels. $(N)$ Light micrograph of a cross section through a sap/ap2-5 flower. The four carpels in whorl 1 are fused to a tube. Ovules in the outer and inner gynoecium are indicated with arrows. Bars, $M$ and $N, 100 \mu \mathrm{m}$. 
division. In these ovules, callose becomes apparent as a group of intensely fluorescing cells at the chalazal region of the nucellus at stage 9 (Fig. 5, cf.E and F), when differentiation of a megasporocyte occurs in wild-type plants. In contrast to sap single mutants, megaspores, either as dyad or tetrad, were never observed in sap/ ap2-1 ovules, indicating that mutations in both genes lead to an arrest in megasporogenesis at earlier stages than in sap single mutants. The fact that ap2-1 ovules display a wild-type phenotype indicates that AP2 is redundant during megasporogenesis and acts in a different pathway to control ovule development other than $S A P$.

We also raised double mutants between sap and stronger alleles of ap2. The ap2-5 mutant allele (Kunst et al. 1989) has carpelloid sepals, which produce occasionally stigmatic tissue (Fig. $5 \mathrm{H}$ ). The petals are reduced in size and the number of fertile stamens is reduced to four or two. No morphological abnormalities are observed in ap2-5 pistils. The ap2-6 (Kunst et al. 1989) is a strong allele with whorl-one organs transformed into unfused carpels and petals completely missing. The reproductive organs are fertile, although the number of stamens is reduced dramatically (Fig. 5I). sap/ap2-5 and sap/ap2-6 double mutants are very similar indicating that the maximum synergistic level is reached (Fig. 5J-L). In both types of double mutants, the four sepals are transformed completely into carpels, which are fused to a gynoeciumlike structure. In side this structure, only the whorl-four pistil is present, whereas petals and stamens are absent. Cross sections through these flowers show that the outer pistil is composed of four carpels bearing ovules at the inner side (Fig. 5M,N). Analysis of the ovules from these double mutants using aniline blue staining for callose deposition revealed a similar abnormality as shown in Figure $5 \mathrm{~F}$ for the sap/ap2-1 double mutant. In conclusion, these double-mutant studies demonstrate that the sap mutant is synergistic to ap2 mutant alleles.

\section{sap/ag-1 double mutants}

Double mutants between sap and the ag-1 mutant allele were generated and displayed a remarkable phenotype (Fig. 6A,D-F). Early-arising sap/ag-1 flowers resemble ag-1 single mutants exhibiting an indeterminate number of whorls of sepals and petals (Fig. 6B,C). The first-whorl organs are not carpel-like as in sap flowers but more sepalloid implying that $A G$ is epistatic to $S A P$ with respect to first-whorl organ identity. The petals in the second whorl of the double mutant are shorter and narrower than the petals in both $a g-1$ and wild-type flowers (Fig. $6 \mathrm{D})$. In contrast to the sap mutant the number of organs in the second and third whorl are as in wild-type flowers. Later-arising sap ag-1 flowers (from approximately seventh flower) produce secondary flower buds in the axils of the second and all subsequent floral whorl organs (Fig. 6D-F). This pattern of floral bud formation reiterates in axillary flowers giving rise to a highly branched inflorescence-like structure (Fig. 6F). When the axillary flowers develop, the regions between the floral whorls elongate forming floral internodes in such a way that the floral
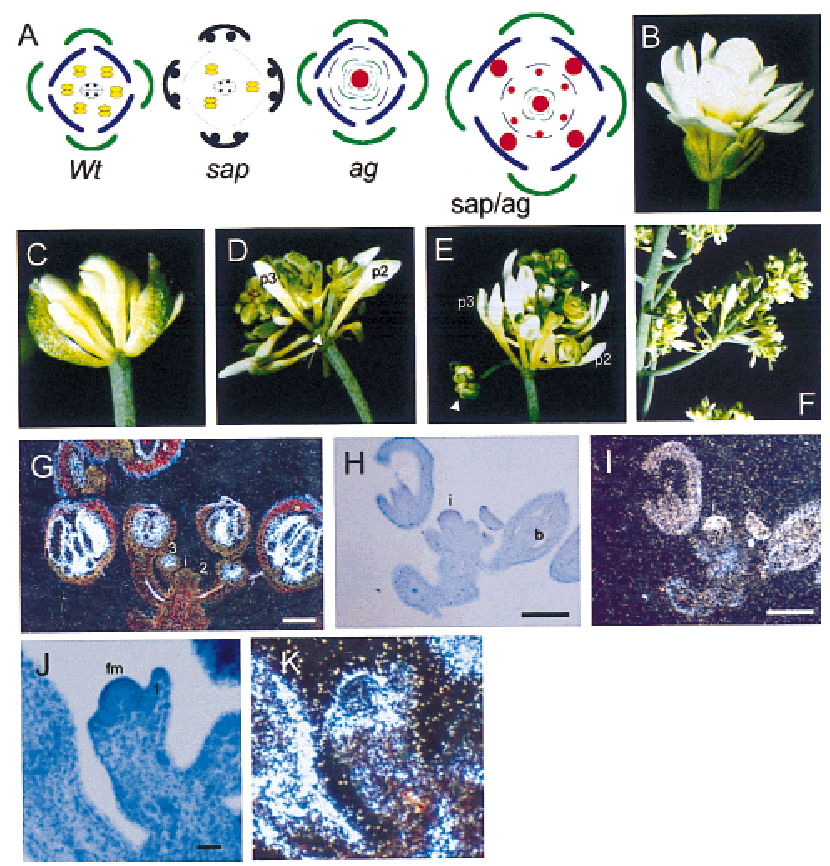

Figure 6. Phenotypes of sap/ag double mutants and expression pattern of $A G$ in wild-type and sap inflorescences. (A) Schematic representation of position and identity of the floral organs in wild-type (wt), sap, ag-1, and sap/ag-1 mutant flowers. Organs are marked as follows: sepals (green); petals (blue); degenerated petals in sap (thin blue lines); stamens (yellow), carpels with ovules (black); new floral buds (red). (B) Phenotype an $a g-1$ mutant flower. (C) Phenotype of an early-arising sap/ag-1 double mutant flower. One sepal was removed to show the inner floral organs. sap/ag-1 flowers are indeterminate with a repeated pattern of sepals-petals-petals from the outermost whorl to the center as in ag-1 single mutants. Compared to wild-type petals, petals of sap/ag-1 are shorter and narrower as in sap. (D-E) Developing sap/ag-1 flowers resembling inflorescences. Secondary flowers, indicated by an arrowhead, develop in axils of the second (p2) and third (p3) whorl petals and all internal floral organs. Internodes are formed between the floral whorls (arrow). (F) Old sap/ag-1 flower producing an inflorescence-like branch. $(G-K)$ Expression of $A G$ was determined by in situ hybridization with ${ }^{35}$ S-labeled antisense RNA. Hybridization signals were viewed using dark-field microscopy. (i) Inflorescence meristem; (b) bud; (fm) floral meristem. (G) Distribution of $A G$ mRNA in a wild-type inflorescence. Signal appears in the center of buds at early stage 3 and in older buds only in stamens and carpels. $(H-I)$ Longitudinal section through a sap inflorescence imaged under bright field $(H)$ or dark field $(I)$. Strong hybridizing signal is visible in the inflorescence meristem and in the entire bud (b). These buds are composed of only carpelloid sepals and a gynoecium in the fourth whorl. $(J-K)$ Longitudinal section through a sap floral meristem at early stage 3 of flower development imaged under bright field $(J)$ or dark field $(K)$. Strong hybridizing signal is visible in a ring around the floral apex. The first-whorl primordia just emerge at the flanks of the meristem.

organs and secondary flowers are arranged in a spiral phyllotaxis rather than a whorled mode as in wild type. These indeterminate flowers display several features of an inflorescence, such as elongated internodes and spiral phyllotaxis. This can be interpreted as a partial reversion from floral to an inflorescence identity. 
The phenotype of sap/ag-1 double mutants demonstrates that characteristics of the sap mutant depend on the presence of an active $A G$ gene, suggesting that $S A P$ repress the expression of $A G$ in the outer two floral whorls. To investigate this in more detail, the distribution of $A G$ mRNA in sap flowers was analyzed. In wildtype flowers, $A G$ is not expressed in inflorescence meristems and stage $1-2$ floral buds (Fig. 6G). At early stage 3 , when the sepal primordia just emerge, $A G$ mRNA is first detectable in the floral apex and not in the sepal primordia. At later developmental stages, hybridization signals were observed in stamen and carpel primordia only. In contrast, high expression levels were detectable in inflorescence meristems of the sap mutant. $A G$ mRNA is also present in all whorls of the highly affected floral buds, which are composed of carpelloid sepals and a developing gynoecium (Fig. 6H,I). In sap flower buds at a stage when the first-whorl organs just emerge at the flanks of the floral meristem (Fig. 6J,K), hybridization signal is detectable in a ring around the floral apex and at a lower level in the first whorl primordia and apex. These data indicate that, unlike wild-type flowers, $A G$ is expressed in inflorescence meristems and at the earliest stages of sap flower formation.

\section{Discussion}

Upon floral induction, the inflorescence meristem normally produces flowers with whorls of distinct organs. We have demonstrated that the Arabidopsis SAP gene, consistent with its mRNA expression pattern, is involved in several floral developmental programs. In concert with $A G$ it is required to maintain floral meristem identity, it controls floral organ identity by suppressing $A G$ activity in the outer whorls and it interacts with AP2 to initiate megasporogenesis in ovules. Sequence comparison revealed that the $S A P$ gene encodes a novel protein with no substantial sequence similarities to other known proteins. However, small domains inside the SAP protein share sequences present in transcriptional regulators, suggesting that SAP may play a role in controlling several developmental programs at the transcriptional level.

\section{$\mathrm{SAP}$ is required for megasporogenesis}

The sap mutant is female sterile, which trait is inherited in a sporophytic manner. Microscopic analysis of the development of sap ovules revealed no obvious aberrations in the ontogeny of the sporophytic tissues of the female reproductive organ, whereas megasporogenesis is arrested after the first meiotic division. These observations imply that $S A P$, as a sporophytically controlled gene, is involved directly in female gametophyte development and presumably plays a crucial role during meiotic cell division. No information is available about the role of $S A P$ in microsporogenesis, because anthers degenerate prematurely in sap mutant plants.

Several mutants that affect female gametophyte devel- opment in Arabidopsis have been described (for review, see Schneitz et al. 1997), though the majority of these mutants display aberrations in sporophytic as well as gametophytic tissues of the ovule. Often, defects in integument development are accompanied by partial or complete absence of magasporogenesis, as it is observed in the sin1, ant and huellenlos (hll) mutants (RobinsonBeers et al. 1992; Lang et al. 1994; Elliott et al. 1996; Klucher et al. 1996; Schneitz et al. 1997). These mutants are referred to as sporophytic and megagametogenesisdefective (smd) mutants by Schneitz et al. (1997). Another class of female defective mutants, from which only a few members have been described (Schneitz et al. 1997) are characterized by defects in gametogenesis and are designated embryo sac-defective (emd) mutants. According to this classification, the sap mutant belongs to the class of megasporogenesis-defective ( $m s d)$ mutants, from which only SAP has been cloned. The emd and msd mutants provide valuable knowledge about the interdependency between sporophytic and gametophytic tissues. Based on the mutants, we conclude that defects in sporophytic tissues often lead to aberrant gametophyte development, however, in contrast sporophyte development is independent from megasporogenesis and megagametogenesis.

\section{SAP genetically interacts with AP2 in various developmental programs}

The SAP gene is strongly expressed in the inflorescence meristem and the emerging floral primordia in wild-type Arabidopsis plants. This pattern of expression overlaps with that of AP2 and it also coincides with AP2 expression at later developmental stages, during floral organogenesis and ovule development. Combined with the resemblance of the phenotypes of the single mutants, we hypothesized that $S A P$ and $A P 2$ interact genetically. Expression analysis revealed that $A P 2$ expression is not affected in the sap mutant and, vice versa, demonstrating that they do not regulate each other at the transcriptional level.

Although both genes are expressed in the inflorescence meristem, the phenotype of the single mutants revealed that only $S A P$ is essential for establishing the inflorescence structure. The complete transformation of sepals into carpels and the absence of petals in the ap2-5/sap and ap2-6/sap double mutants indicate that the genes are synergistic.

Another intriguing aspect of the interaction between $S A P$ and $A P 2$ is the more dramatic defect observed during ovule development. Megasporogenesis in all double mutants analyzed appears to be arrested at even an earlier stage than in the sap single mutant, whereas the ap2 mutant alleles are normally fertile. This new phenotype indicates that both genes $S A P$ and $A P 2$ are involved in the initiation of megasporogenesis and are able to complement each other at this stage. This ascribes a new function for $A P 2$, which is normally masked by redundancy of genes also involved in this process. Because in sap ovules the development proceeds until the second 
meiotic division, $S A P$ is dispensable for the initial stage of megasporogenesis but absolutely required for later processes. The fact that the aberrations in the sap mutant are inherited as a recessive trait indicates that SAP is a sporophytically expressed gene controlling the reduction to haploid spore cells.

\section{SAP genetically interacts with AG to maintain floral meristem identity}

sap/ag-1 double mutants display several interesting transformations with respect to floral architecture as well as meristem identities. First, the restoration of the first-whorl organ identity to sepals and the formation of petals in the second and third whorls demonstrate that the role of $S A P$ in these whorls depends on $A G$ expression.

A second feature of the double mutant is the formation of axillary flower buds in the axils of the organs in the second and all subsequent whorls. The organs in these whorls and the axillary flowers are arranged in a spiral phyllotaxy, which is typical for inflorescences. Similar inflorescence-like characteristics and reversions to inflorescence shoot meristem are present in ap 1 and 1 fy single and ag/ap1, ag/lfy double mutants (Bowman et al. 1993; Weigel et al. 1992; Schultz and Haughn 1991). Even in $a g$ single mutants grown under short day conditions, reversions of the indeterminate floral meristem to the indeterminate inflorescence meristem occurs independently from the early acting genes AP1 and LFY (Mizukami and Ma 1997). Because single sap and ag mutant flowers grown under our conditions do not exhibit transformations into inflorescence-like structures, the phenotype of the double mutant indicates that $S A P$ acts locally in concert with $A G$ either to maintain or to promote floral meristem fate. The residual floral character of the transformed flowers is revealed by the presence of sepal and petal-like organs and implies that $S A P$ and $A G$ interact in a local manner similar to $A P 1$. Most likely, the early acting meristem identity genes $L F Y$ and $A P 1$ initiate a determinate floral meristem, whereas several other genes are required for the final definition of floral meristem identity. Here, we demonstrated that at least two genes, $S A P$ and $A G$, facilitate in part the final definition of floral meristem identity in Arabidopsis.

\section{$\mathrm{SAP}$ is a negative regulator of $\mathrm{AG}$}

One of the functions of $A P 2$ is to prevent ectopic expression of the $A G$ gene in the perianth whorls, but $A P 2$ seems not to be capable of suppressing $A G$ on its own (Drews et al. 1991; Okamuro et al. 1993; Jofuku et al. 1994). Recently, it was shown that two other genes, LEUNIG (LUG) and CURLY LEAF (CLF) may play a role in concert with $A P 2$ to repress $A G$ in the first- and second-whorl organs of Arabidopsis flowers (Liu and Meyerowitz 1995; Goodrich et al. 1997). lug mutants are characterized by narrow leaves and floral organs and display an enhanced ap2 phenotype with respect to floral- organ identity. Mutations in CLF cause severe effects on leaf morphology and on flowering time. In addition, the flowers of clf are very similar to ap2 flowers, though the petals are smaller and narrower compared to petals of weak ap2 alleles. Double-mutant analysis and misexpression of $A G$ in ap2, lug, and clf mutants have demonstrated that these genes act as negative regulators of $A G$ at different stages of development (Drews et al. 1991; Liu and Meyerowitz 1991; Goodrich et al. 1997). AP2 and $L U G$ are both required for the initial specification of $A G$ expression pattern from stage 2 onwards. In clf mutants, $A G$ is expressed ectopically in hypocotyls, cotelydons, leaves, and at later floral stages (from stage 9) in the petals. This suggests that CLF is needed to maintain the suppression at later developmental stages.

Several observations provide evidence that $S A P$, like $A P 2, L U G$, and $C L F$, is a cadastral gene negatively regulating $A G$ expression. First, the phenotype of sap single and ap2/sap double mutants show striking similarities to that of plants in which $A G$ was constitutively expressed (Mizukami and Ma 1992). The double mutants exhibit more severe homeotic transformation in flowers than either single mutant. This corroborates our suggestion that $S A P$ is one of the partners of $A P 2$ to suppress $A G$. Secondly, in $a g / s a p$ double mutants sepals and petals develop, which demonstrates that for SAP action in the perianth organs $A G$ expression is needed. Furthermore, it shows that $S A P$ is not a floral organ identity gene required to specify sepal and petal identity. Finally, our in situ hybridization experiments reveal that $A G$ is misexpressed in the inflorescence meristem and during the initial stages of sap floral organ development. We did not detect $S A P$ expression in sepal primordia and in flower buds after developmental stage 7 , suggesting that another regulator causes the carpelloidy in the first whorl of sap mutants. Alternatively, the carpelloidy is already established before the sepal primordia emerge (before stage 2), when SAP mRNA is present and $A G$ is ectopically expressed in a sap mutant background. The role of $S A P$ in specifying the spatial expression of $A G$ is additive to that of the other cadastral genes $A P 2, L U G$, and $C L F$, because none of these regulators control $A G$ in the inflorescence meristem.

This report and earlier observations with $A P 2, L U G$, and $C L F$, demonstrates that a complex pattern of spatially restricted genes, each acting at different developmental stages is required to co-ordinatively regulate the expression of the homeotic gene $A G$.

\section{Materials and methods}

\section{Plant material}

A. thaliana ecotype Landsberg erecta was used in this work. All plants were grown under standard greenhouse conditions $(16 \mathrm{hr}$ light; $\left.20-22{ }^{\circ} \mathrm{C}\right) . \mathrm{T}_{3}$ seeds of two En/Spm-I/dSpm transposoncontaining lines were used for the screening for sterile mutants (Aarts et al. 1995). The original sap::I/dSpm transposon-tagged mutant was found in the line H32.3 containing 10 different I/dSpm elements. 
Seeds of ag-1 and ap2 mutant alleles were obtained from the Arabidopsis Biological Resource Center (Columbus, OH).

\section{Construction of double mutants}

sap/ap2 As sap mutant plants are completely sterile we pollinated Sap,sap::I/dSpm heterozygous flowers with ap2 pollen. $\mathrm{F}_{1}$ progeny of those crosses were all phenotypically normal. Seeds obtained from a few self-fertilized $\mathrm{F}_{1}$ plants were harvested and the progenies were analyzed. As the ap2-5 and ap2-6 mutants were in the Columbia genetic background the appearance of the $\mathrm{F}_{2}$ plants varied slightly with respect to size and internode length depending on the genetic background. Among the $\mathrm{F}_{2}$ progeny four flower phenotypes were observed consistent with a 9:3:3:1 ratio, as listed below. For sap/ap2-1, the distribution of $\mathrm{F}_{2}$ plants was 173 wild-type, 51 ap2-1, 54 sap, and 18 plants with a novel phenotype (ratio 9:3:3:1; $\chi 2=0.013 ; P>0.9$ ). For sap/ ap2-5, the distribution of $\mathrm{F}_{2}$ plants was 71 wild-type, 21 ap2-5 19 sap, and 8 plants with a novel phenotype (ratio 9:3:3:1; $\chi^{2}=0.75 ; P>0.9$. For sap/ap2-6, the distribution of $\mathrm{F}_{2}$ plants was 57 wild type, 20 ap2-5, $16 \mathrm{sap}$, and 6 plants with a novel phenotype (ratio 9:3:3:1; $\chi_{1}^{2}=0.5 ; P>0.9$ ). Some of the plants with the novel phenotype produced revertant branches with a normal length of the internodes (in $\mathrm{F}_{2}$ sap/ap2-1) and with fertile ap2 flowers indicating that they represented sap/ap2 double mutants.

sap/ag-1 To obtain sap/ag-1 double mutants stable, heterozygous Sap,sap::I/dSpm plants were crossed with the $A g, a g-1$ plants. Among the $\mathrm{F}_{2}$ progenies obtained from Ag,ag-1/Sap, sap::I/dSpm self-pollinated plants four different phenotypes were found represented by 159 wild-type, 55 ag-1, 50 sap, and 17 plants with a novel phenotype (ratio 9:3:3:1; $\chi^{2}=0.26 ; P>0.90$ ). A few plants with the novel phenotype had revertant branches with ag-1-like flowers, indicating that the new phenotype belonged to sap/ag-1 double mutants.

\section{Inverse PCR analysis}

DNA flanking the $I / d S p m$ element was obtained by IPCR as described by Aarts (1996). The resulting IPCR product was cloned in pMOSBlueT-vector (Amersham) and sequenced with the ABI Prism Dye Terminator Cycle Sequencing Ready Reaction Kit (Perkin Elmer).

\section{Mapping of the SAP locus}

For the mapping of $S A P$, a PCR fragment obtained by using the $S A P$ gene-specific primer 1 (5'-TCGACTCATTTAAGGCTTC$\left.3^{\prime}\right)$ and primer 2 (5'-CAGTGCACCGAAATCCCATAGATG$3^{\prime}$ ), was used as RFLP probe. This probe was hybridized to a blot containing the SstI-digested DNAs of 98 RILs (Lister and Dean 1993). Recombination frequencies and map distances were calculated with the JoinMap program (Stam 1993), using mapping data provided by C. Lister and C. Dean (Cambridge Laboratory, John Innes Institute, Norwich, UK).

\section{Genomic library screening}

A Landsberg erecta genomic library, obtained through the Arabidopsis Biological Resource Center (Ohio State University, Columbus, $\mathrm{OH}$ ) and the European DNA Resource Centre (MaxDelbrück Laboratory, Köln, Germany), was screened with the $S A P$-specific IPCR fragment as a probe. Hybridizations were done as described previously (Angenent et al. 1992).

\section{DNA and RNA analysis}

Genomic DNA from Arabidopsis leaves was isolated as described by Aarts (1996), and $400 \mathrm{ng}$ was digested, electrophorized, and blotted onto Hybond N+ membranes. Blots were hybridized according to Angenent et al. (1992) and washed with $0.1 \times$ SSC at $65^{\circ} \mathrm{C}$.

Poly $(\mathrm{A})^{+}$RNA from different Arabidopsis tissues was isolated using a QuickPrep Micro mRNA Purification Kit as described by manufacturer (Pharmacia Biotech), and $5 \mu$ g was denaturated by glyoxal $(1.5 \mathrm{M})$ prior to electrophoresis. Hybridization was performed according to Angenent et al. (1992).

\section{In situ hybridization}

The plant material was fixed at $40^{\circ} \mathrm{C}$ for 2 days in $4 \%$ formaldehyde, $5 \%$ acetic acid, $50 \%$ ethanol, and stepwise dehydrated until $100 \%$ ethanol prior to infiltration with xylene and subsequent embedding in paraffin and sectioning. Sections treated with paraffin and rehydrated were taken according to the in situ hybridization procedure essentially as described by Angerer and Angerer (1991). The complete SAP cDNA was used for generating the antisense probe. The $A G$ antisense RNA contained nucleotides 240-977 of the $A G$ sequence published in Yanofsky et al. (1990). Hybridization was done at $42^{\circ} \mathrm{C}$ in $2.25 \times$ SSPE ( $1 \times$ SSPE: $0.18 \mathrm{M} \mathrm{NaCl}, 0.001 \mathrm{M} \mathrm{NaPO}_{4}$ at $\mathrm{pH} 7.7,0.001 \mathrm{M} \mathrm{EDTA),}$ $50 \%$ formamide, and washed at $42^{\circ} \mathrm{C}$ in $0.1 \times$ SSC, $50 \%$ formamide. Sections were exposed for 2-4 weeks (AG probe) and 8 weeks (SAP probe). Photographs were taken with a Diaplan microscope equipped with dark-field optics (Leitz, Wetzlar, Germany).

\section{5' RACE}

5' RACE was performed according to the protocol of the Marathon cDNA Amplification Kit (Clontech). Briefly, $1 \mu \mathrm{g}$ of polyadenylated RNA from young flower buds (stages 0-6) was used as a template for first-strand cDNA synthesis. The first PCR was performed using adaptor primer 1 and the SAP genespecific primer $3\left(5^{\prime}\right.$-GTGTGACCAACACCGTCTATTTCCG$\left.3^{\prime}\right)$, which corresponds to nucleotides 713-739 of SAP cDNA. A second round of PCR was done using adaptor primer 2 and a nested gene-specific primer $4\left(5^{\prime}\right.$-ATCCGTCGGCGAACCCTCCG-3'), corresponding to nucleotides 537-555 of SAP cDNA. The resulting 5 -RACE-PCR product of $555 \mathrm{bp}$ in length was cloned and sequenced as described before. The accession number of the SAP cDNA sequence is AJ223125.

\section{Callose and pollen tube staining in ovaries}

Pollen tube growth and callose deposition were visualized by staining with aniline blue as described previously (Angenent et al. 1993).

\section{Acknowledgments}

We thank Ruth De Groodt for technical assistance with in situ hybridization experiments and Andy Perreira and Arjen van Tunen for kindly providing the transposon lines and helpful discussions. Gerrit Stunnenberg is acknowledged for taking care of the plants. Ap2 and ag mutant alleles were derived from the Arabidopsis Biological Research Center (Columbus, OH). This research was supported by the Graduate School of Experimental Plant Sciences (EPS) with a fellowship awarded to M.V.B. This project was partially financed by the Dutch Organization for Scientific Research (NWO). 
The publication costs of this article were defrayed in part by payment of page charges. This article must therefore be hereby marked 'advertisement' in accordance with 18 USC section 1734 solely to indicate this fact.

\section{References}

Aarts, M.G.M. 1996. 'An En/Spm based transposable element system for gene isolation in Arabidopsis thaliana.' $\mathrm{PhD}$ thesis, Wageningen Agricultural University, Wageningen, The Netherlands.

Aarts, M.G.M., P. Corzaan, W.J. Stiekema, and A. Pereira. 1995. A two-element Enhancer-Inhibitor transposon system in Arabidopsis thaliana. Mol. Gen. Genet. 247: 555-564.

Altschul, S.F., W. Giish, W. Miller, E.W. Myers, and D.J. Lipman. 1990. Basic local alignment search tool. J. Mol. Biol. 215: 403-410.

Angenent, G.C., M. Busscher, J. Franken, J.N.M. Mol, and A.J. van Tunen. 1992. Differential expression of two MADS box genes in wild-type and mutant petunia flowers. Plant Cell 4: 983-993.

Angenent, G.C., J. Franken, M. Busscher, L. Colombo, and A.J. van Tunen. 1993. Petal and stamen formation in petunia is regulated by the homeotic gene FBP1. Plant J. 3: 101-112.

Angerer, L.M. and R.C. Angerer. 1991. Localization of mRNAs by in situ hybridization. Methods Cell Biol. 35: 37-71.

Bowman, J.L., D.R. Smyth, and E.M. Meyerowitz. 1991. Genetic interactions among floral homeotic genes of Arabidopsis. Development 112: 1-20.

Bowman, J.L., J. Alvazer, D. Weigel, E.M. Meyerowitz, and D.R. Smyth. 1993. Control of flower development in Arabidopsis thaliana by APETALA1 and interacting genes. Development 119: $721-743$.

Coen, E.S. and E.M. Meyerowitz. 1991. The war of the whorls: Genetic interactions controlling flower development. $\mathrm{Na}$ ture 353: 31-37.

Drews, G.N., J.L. Bowman, and E.M. Meyerowitz. 1991. Negative regulation of the Arabidopsis gene AGAMOUS by the APETALA2 product. Cell 65: 991-1002.

Elliott, R.C., A.S. Betzner, E. Huttner, M.P. Oakes, W.Q.J. Tucker, D. Gerentes, P. Perez, and D.R. Smyth. 1996. AINTEGUMENTA, an APETALA2-like gene of Arabidopsis with pleiotropic roles in ovule development and floral organ growth. Plant Cell 8: 155-168.

Gaiser, J.C., K. Robinson-Beers, and C.S. Gasser. 1995. The Arabidopsis SUPERMAN gene mediates asymmetric growth of the outer integument of ovules. Plant Cell 7: 333-345.

Gashler, A.L., S. Swaminathan, and V.P. Sukhatme. 1993. A novel repression module, an extensive activation domain, and a bipartite nuclear localisation signal defined in the immediate-early transcription factor Egr-1. Mol. Cell. Biol. 13: 4556-4571.

Goodrich, J., P. Puangsomlee, M. Martin, D. Long, E.M. Meyerowitz, and G. Coupland. 1997. A polycomb-group gene regulates homeotic gene expression in Arabidopsis. Nature 386: $44-51$.

Gubler, U. and B.J. Hoffman. 1983. A simple and very efficient method for generating complimentary DNA libraries. Gene 25: 263-269.

Huala, E. and I.M. Sussex. 1992. LEAFY interacts with floral homeotic genes to regulate Arabidopsis floral development. Plant Cell 4: 901-913.

Hülskamp, M., K. Schneitz, and R.E. Pruitt. 1995. Genetic evidence for a long-range activity that directs pollen tube guidance in Arabidopsis. Plant Cell 7: 57-64.
Irish, V.F. and I.M. Sussex. 1990. Function of the APETALA1 gene during Arabidopsis floral development. Plant Cell 2: 741-753.

Janssen-Timmen, U., P. Lemaire, M.-G. Mattei, O. Revelant, and P. Charnay. 1989. Structure, chromosome mapping and regulation of the mouse zinc-finger gene Krox-24; evidence for a common regulatory pathway for immediate-early serum-response genes. Gene 80: 325-336.

Jofuku, K.D., B.G.W. den Boer, M. Van Montagu, and J.K. Okamuro. 1994. Control of Arabidopsis flower and seed development by the homeotic gene APETALA2. Plant Cell 6: 1211-1225.

Kempin, S.A., B. Savidge, and M. Yanofsky. 1995. Molecular basis of the cauliflower phenotype in Arabidopsis. Science 267: 522-525.

Klucher, K.M., H. Chow, L. Reiser, and R.L. Fischer. 1996. The AINTEGUMENTA gene of Arabidopsis required for ovule and female gametophyte development is related to the floral homeotic gene APETALA2. Plant Cell 8: 137-153.

Komaki, M.K., K. Okada, E. Nishino, and Y. Shimura. 1988. Isolation and characterization of novel mutants of Arabidopsis thaliana defective in flower development. Development 104: 195-203.

Kunst, L., J.E. Klenz, J. Martinez-Zapater, and G.W. Haughn. 1989. AP2 gene determines the identity of perianth organs in flowers of Arabidopsis thaliana. Plant Cell 1: 1195-1208.

Lang, J.D., S. Ray, and A. Ray. 1994. sin1, a mutation affecting female fertility in Arabidopsis, interacts with mod1, its recessive modifier. Genetics 137: 1101-1110.

Léon-Kloosterziel, K.M., C.J. Keijzer, and M. Koornneef. 1994. A seed shape mutant of Arabidopsis that is affected in integument development. Plant Cell 6: 385-392.

Lister, C. and C. Dean. 1993. Recombinant inbred lines for mapping RFLP and phenotypic markers in Arabidopsis thaliana. Plant J. 4: 745-750.

Liu, Z. and E.M. Meyerowitz. 1995. LEUNIG regulates AGAMOUS expression in Arabidopsis flowers. Development 121: 975-991.

Mandel, M.A. and M.F. Yanofsky. 1995. A gene triggering flower formation in Arabidopsis. Nature 377: 522-524.

Mandel, M.A., C. Gustafson-Brown, B. Savidge, and M.F. Yanofsky. 1992. Molecular characterization of the Arabidopsis floral homeotic gene APETALA1. Nature 360: 273-277.

Mitchell, P.J. and R. Tiian. 1989. Transcriptional regulation in mammalian cells by sequence-specific DNA binding proteins. Science 245: 371-378.

Mizukami, Y. and H. Ma. 1992. Ectopic expression of the floral homeotic gene AGAMOUS in transgenic Arabidopsis plants alters floral organ identity. Cell 71: 119-131.

. 1995. Separation of $A G$ function in floral meristem determinacy from that in reproductive organ identity by expressing antisense AG RNA. Plant Mol. Biol. 28: 767-784.

- 1997. Determination of Arabidopsis floral meristem identity by AGAMOUS. Plant Cell 9: 393-408.

Modrusan, Z., L. Reiser, K.A. Feldmann, R.L. Fischer, and G.W. Haughn. 1994. Homeotic transformation of ovules into carpel-like structures in Arabidopsis. Plant Cell 6: 333-349.

Okamuro, J.K., B.G.W. den Boer, and K.D. Jofuku. 1993. Regulation of Arabidopsis flower development. Plant Cell 5: 1183-1193.

Pimienta, E. and V.S. Polito. 1982. Ovule abortion in 'Nonpareil' almond (Prunus dulcis [Mill.] D.A. Webb). Am. J. Bot. 69: 913-920.

Reiser, L., Z. Modrusan, L. Margossian, A. Samach, N. Ohad, G.W. Haughn, and R.L. Fischer. 1995. The BELL1 gene encodes a homeodomain protein involved in pattern formation 
Byzova et al.

in the Arabidopsis ovule primordium. Cell 83: 735-742.

Robinson-Beers, K., R.E. Pruitt, and C.S. Gasser. 1992. Ovule development in wild-type Arabidopsis and two female-sterile mutants. Plant Cell 4: 1237-1249.

Rodkiewicz, B. 1970. Callose in cell walls during megasporogenesis in angiosperms. Planta 93: 39-47.

Sakai, H., L.J. Medrano, and E.M. Meyerowitz. 1995. Role of SUPERMAN in maintaining Arabidopsis floral whorl boundaries. Nature 378: 199-203.

Schneitz, K., M. Hülskamp, and R.E. Pruitt. 1995. Wild-type ovule development in Arabidopsis thaliana: A light microscope study of cleared whole-mount tissue. Plant I. 7: 731749.

Schneitz, K., M. Hülskamp, S.D. Kopczak, and R.E. Pruitt. 1997. Dissection of sexual organ ontogenesis: A genetic analysis of ovule development in Arabidopsis thaliana. Development 124: $1367-1376$

Schultz, E.A. and G.W. Haughn. 1991. LEAFY, a homeotic gene that regulates inflorescence development in Arabidopsis. Development 119: 745-765.

Smyth, D.R., J.L. Bowman, and E.M. Meyerowitz. 1990. Early flower development in Arabidopsis. Plant Cell 2: 755-767.

Stam, P. 1993. Construction of integrated genetic linkage maps by means of a new computer package: JoinMap. Plant $J$. 3: 739-744.

Vishnyakova M.A. 1991. Callose as an indicator of sterile ovules. Phytomorphology 41: 245-252.

Weigel, D. 1995. The genetics of flower development: From floral induction to ovule morphogenesis. Annu. Rev. Genetics 29: 19-39.

Weigel, D., J. Alvarez, D.R. Smyth, M.F. Yanofsky, and E.M. Meyerowitz. (1992). LEAFY controls floral meristem identity in Arabidopsis. Cell 69: 843-859.

Yanofsky, M.F., H. Ma, J.L. Bowman, G.N. Drews, K.A. Feldmann, and E.M. Meyerowitz. 1990. The protein encoded by the Arabidopsis homeotic gene AGAMOUS resembles transcriptional factors. Nature 346: 35-39.

Yanofsky, M. 1995. Floral meristems to floral organs: Genes controlling early events in Arabidopsis flower development. Annu. Rev. Plant Physiol. Plant Mol. Biol. 46: 167-188. 


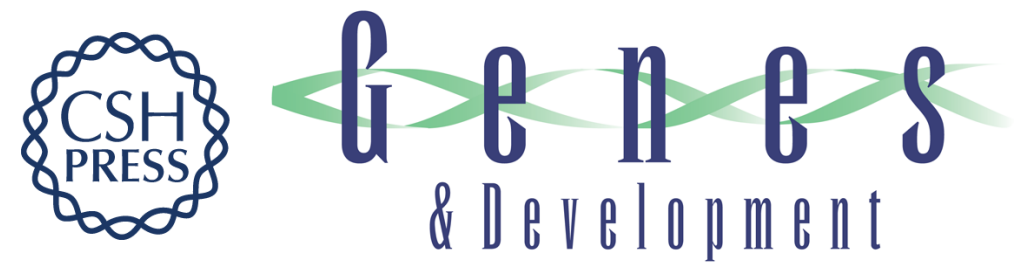

\section{Arabidopsis STERILE APETALA, a multifunctional gene regulating inflorescence, flower, and ovule development}

Marina V. Byzova, John Franken, Mark G.M. Aarts, et al.

Genes Dev. 1999, 13:

References This article cites 48 articles, 25 of which can be accessed free at:

http://genesdev.cshlp.org/content/13/8/1002.full.html\#ref-list-1

License

Email Alerting Receive free email alerts when new articles cite this article - sign up in the box at the top

Service right corner of the article or click here.

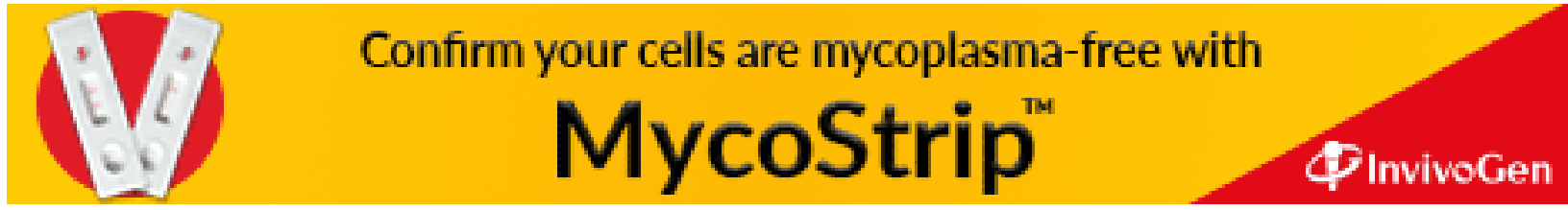

